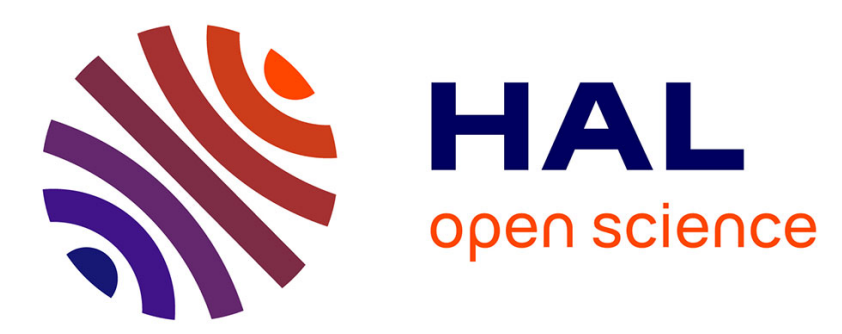

\title{
Controlling the Crystalline Quality and the Purity of Single-walled Carbon Nanotubes Grown by Catalytic Chemical Vapor Deposition
}

Hugo Navas, Matthieu Picher, Raul Arenal, Etienne Quesnel, Eric Anglaret, Vincent Jourdain

\section{To cite this version:}

Hugo Navas, Matthieu Picher, Raul Arenal, Etienne Quesnel, Eric Anglaret, et al.. Controlling the Crystalline Quality and the Purity of Single-walled Carbon Nanotubes Grown by Catalytic Chemical Vapor Deposition. 2012. hal-00802071

\author{
HAL Id: hal-00802071 \\ https://hal.science/hal-00802071 \\ Preprint submitted on 18 Mar 2013
}

HAL is a multi-disciplinary open access archive for the deposit and dissemination of scientific research documents, whether they are published or not. The documents may come from teaching and research institutions in France or abroad, or from public or private research centers.
L'archive ouverte pluridisciplinaire HAL, est destinée au dépôt et à la diffusion de documents scientifiques de niveau recherche, publiés ou non, émanant des établissements d'enseignement et de recherche français ou étrangers, des laboratoires publics ou privés. 


\title{
Controlling the Crystalline Quality and the Purity of Single-walled Carbon Nanotubes Grown by Catalytic Chemical Vapor Deposition
}

\author{
Hugo Navas ${ }^{1,2}$, Matthieu Picher ${ }^{1,2}$, Raul Arenal ${ }^{3,4,5}$, Etienne Quesnel6 ${ }^{6}$ Eric Anglaret $^{1,2}$, \\ Vincent Jourdain ${ }^{1,2}$ \\ ${ }^{1}$ Université Montpellier 2, Laboratoire Charles Coulomb UMR 5221, F-34095 Montpellier, \\ France \\ ${ }^{2}$ CNRS, Laboratoire Charles Coulomb UMR 5221, F-34095 Montpellier, France \\ ${ }^{3}$ Laboratoire d'Etude des Microstructures, UMR 104 CNRS-ONERA, 29 av. de la Division \\ Leclerc, 92322 Châtillon, France \\ ${ }^{4}$ Laboratorio de Microscopias Avanzadas (LMA), Instituto de Nanociencia de Aragon (INA), U. \\ Zaragoza, C/ Mariano Esquillor s/n, 50018 Zaragoza, Spain \\ ${ }^{5}$ Fundacion ARAID, 50004 Zaragoza, Spain \\ ${ }^{6}$ CEA-LITEN, 17 rue des Martyrs, 38054 Grenoble cedex 9, France
}

\begin{abstract}
It is frequently observed that as-grown single-walled carbon nanotubes (SWCNTs) contain defects. Controlling the defect density is a key issue for the control of nanotube properties. However, little is known about the influence of the growth conditions on the formation of nanotube defects. In addition, SWCNT samples frequently contain carbonaceous by-products which affect their ensemble properties. Raman spectroscopy is commonly used to characterize both features from the measurement of the defect-induced D band. However, the contribution of each carbonaceous species to the $\mathrm{D}$ band is usually not known making it difficult to separately extract the defect density and relative abundance of each. Here, we report on the correlated evolution of the D and G' bands of SWCNT samples with increasing growth temperature. In the general case, three to four Lorentzian components are required to fit them. Coupled with HRTEM characterization, the low frequency components of the D and G' can be attributed to the contribution of SWCNTs while high frequency components are associated with defective carbonaceous by-products. The nature of these defective by-products varies with the type of catalysts and with the growth conditions.
\end{abstract}

\section{INTRODUCTION}

Raman spectroscopy is commonly used to assess defects in graphene-related materials $[1,2]$ through the measurement of the intensity ratio of the defect-induced D band to the graphenic $\mathrm{G}$ band $[3,4]$. The Raman $\mathrm{D}$ band is activated in the presence of defects through a double resonance process involving the elastic scattering of electrons by defects $[5,6]$. When the distance between defects $\left(\mathrm{L}_{\mathrm{D}}\right)$ is larger than a few $\mathrm{nm}$, the $\mathrm{I}_{\mathrm{G}} / \mathrm{I}_{\mathrm{D}}$ ratio is inversely proportional to the density of defects [7]. The D-band profile is also dependent on the type and structure of $\mathrm{sp}^{2}$ carbon material. For instance, Souza Filho et al. [8] showed that for SWCNTs, the frequency of the $\mathrm{D}$ band depends on the nanotube diameter following the general trend $\omega_{\mathrm{D}}=1354.8-16.5 / \mathrm{d}$ for $\mathrm{E}_{\text {laser }}=2.41 \mathrm{eV}$. Flat single-layer graphene with a small amount of defects displays a quite narrow D-band with a linewidth around $20 \mathrm{~cm}^{-1}$ which broadens for $\mathrm{L}_{\mathrm{D}}<5 \mathrm{~nm}$ [7]. Graphitic $\mathrm{sp}^{2}$ carbon materials (graphite polyhedral crystal, graphite whiskers) can also display D-band linewidth around $20 \mathrm{~cm}^{-1}$ [9] while less ordered materials (CVD multi-walled nanotubes [10], turbostratic carbon [9], short stacked graphene patches [11], polycrystalline graphite [12] 
amorphous carbon [13]...) display a broad D band with linewidths ranging from $45 \mathrm{~cm}^{-1}$ to 100 $\mathrm{cm}^{-1}$.

The D band of a SWCNT sample is generally considered as the sum of two contributions: a first one related to SWCNT defects and a second one related to defective carbonaceous impurities. However, the nature and abundance of the defective by-products (pyrolitic amorphous carbon, catalytically-grown defective carbon structures, carbon filaments, carbon shells, $\mathrm{C}_{\mathrm{x}} \mathrm{H}_{\mathrm{y}}$ polymers...) is usually poorly known making it difficult to determine the defect density of SWCNTs as a function of the growth conditions. Here, we report on our investigations for identifying the relative contributions of the different carbon species in the $\mathrm{D}$ band and its second-order mode, the G' (or 2D) band for CNT samples grown in different CCVD conditions.

\section{EXPERIMENT}

Catalysts consisted of $5 \AA$-thick layers of cobalt deposited on $\mathrm{SiO}_{2} / \mathrm{Si}$. Before nanotube growth, the catalysts were calcined at $700^{\circ} \mathrm{C}$ under air. A cell equipped with a resistive heating crucible, an integrated thermocouple and a silica window was used to perform CNT syntheses monitored in situ by Raman measurements. Gaseous feeds (argon, acetylene, ethanol) were supplied through mass flow controllers while the supply of ethanol vapours was achieved by a thermo-regulated bubbler. High resolution transmission electron microscopy (HRTEM) has been performed using a FEI Tecnai F20 field-emission microscope working at $200 \mathrm{kV}$. Raman measurements were performed with a Jobin Yvon T-64000 spectrometer (simple or triple grating configurations) at either $532 \mathrm{~nm}$ or $647 \mathrm{~nm}$ exciting lines(laser energies of 2.33 and $1.92 \mathrm{eV}$, respectively) with a $x 50$ objective. We previously showed that the intrinsic D band of SWCNTs grown by CCVD can be masked by other effects, notably the deposition of pyrolytic carbon during CCVD or the sample modification by air exposure [14]. Hereafter, we only consider growth conditions that displayed no sign of pyrolytic carbon deposition during the in situ Raman monitoring of the growth (i.e. no increase and broadening of the $\mathrm{D}$ band with increasing temperature, no decrease of the $\mathrm{G}$ band and of silicon peaks with synthesis time). Under these conditions, the Raman spectra can be considered free of pyrolytic carbon contributions and characteristic of catalytically-grown carbon structures. In addition, all the post-growth Raman data presented hereafter were recorded under argon just after cooling the sample to room temperature to prevent sample modifications under air.

\section{RESULTS}

Given these precautions, the D band displays the features shown in Figure 1. One can observe a downshift and narrowing of the $\mathrm{D}$ band with increasing synthesis temperature. A closer look actually reveals that the D-band displays an asymmetric profile. In first approach, the $\mathrm{D}$ band of these samples can be considered as the sum of two contributions: a narrow $\mathrm{D}_{\mathrm{L}}$ peak at $\omega_{\mathrm{DL}} \sim 1300 \mathrm{~cm}^{-1}$ and a broader $\mathrm{D}_{\mathrm{H}}$ band at $\omega_{\mathrm{DH}} \sim 1322 \mathrm{~cm}^{-1}$ (for $\mathrm{E}_{\text {laser }}=$ of $1.92 \mathrm{eV}$ ). Importantly, the $\mathrm{D}_{\mathrm{L}}$ component is best resolved for SWCNT samples displaying intense radial breathing modes characteristic of very small-diameter SWCNTs $(\sim 0.8 \mathrm{~nm})$. The $\mathrm{D}_{\mathrm{H}}$ component can be correctly fitted by a broad Lorentzian component but, for some spectra, two or three narrow Lorentzian components are required as shown in Figure 1. This suggests that the broad $\mathrm{D}_{\mathrm{H}}$ band is actually composed of several individual components. One can observe that the intensity of the high-frequency components decreases with increasing temperature.

We also studied the evolution of the G' band which is the two-phonon process associated to the one-phonon process causing the $\mathrm{D}$ band scattering. While the $\mathrm{D}$ band is only activated in 
the presence of defects, the $G^{\prime}$ band is an intrinsic feature of graphene-related systems. One can observe in Figure 1 that the G' band of the samples also displays an asymmetric shape. Three or four Lorentzian peaks (depending on the precursor-catalyst-system) are required to correctly fit its profile. Like for the D band, the position of each Lorentzian feature remains quite constant whatever the growth temperature but the relative intensities vary significantly. The evolution of the $\mathrm{G}^{\prime}$ profile is well correlated with that of the D band: similarly to the high-frequency components of the D-band, the high-frequency components of the G' band decrease in intensity with increasing growth temperature.

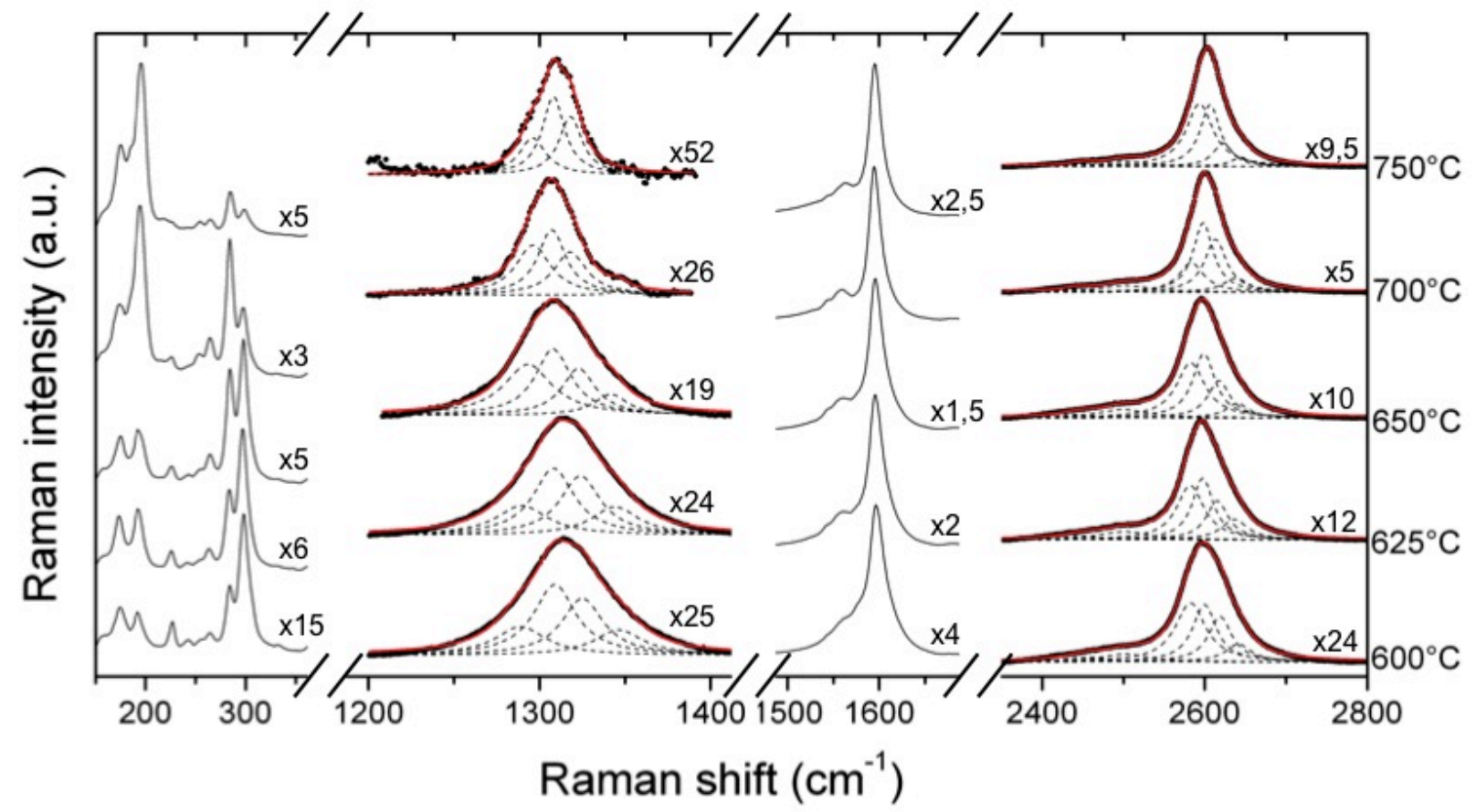

Figure 1. Evolution of the Raman features of the samples with increasing growth temperature for $\mathrm{Co} / \mathrm{SiO}_{2}$ as catalyst and $80 \mathrm{~Pa}$ of EtOH. The laser energy is $1.92 \mathrm{eV}$.

A good match is observed between the frequencies of the $\mathrm{G}^{\prime}{ }_{i}$ and of the corresponding $\mathrm{D}_{\mathrm{i}}$ component with the same $\mathrm{i}$ value (Figure 2). The frequency of the $\mathrm{G}^{\prime}{ }_{\mathrm{i}}$ component is not exactly the double of the $\mathrm{D}_{\mathrm{i}}$ frequency but is usually lower by several $\mathrm{cm}^{-1}$ in agreement with the $\omega_{\mathrm{D}^{-}}$ $\omega_{\mathrm{G}}, / 2$ difference of $4-5 \mathrm{~cm}^{-1}$ reported in the literature and accounted for by the different possible scattering mechanisms associated with the D band (defect first or phonon first) [1]. In addition with the correlated evolution as a function of the temperature, this match in frequency further supports that the $\mathrm{G}^{\prime}{ }_{i}$ and $\mathrm{D}_{\mathrm{i}}$ peaks with same $\mathrm{i}$ values are associated. A major difference between the $\mathrm{D}$ and $\mathrm{G}$ ' bands is that the high-frequency components are much more intense in the former than in the latter. 


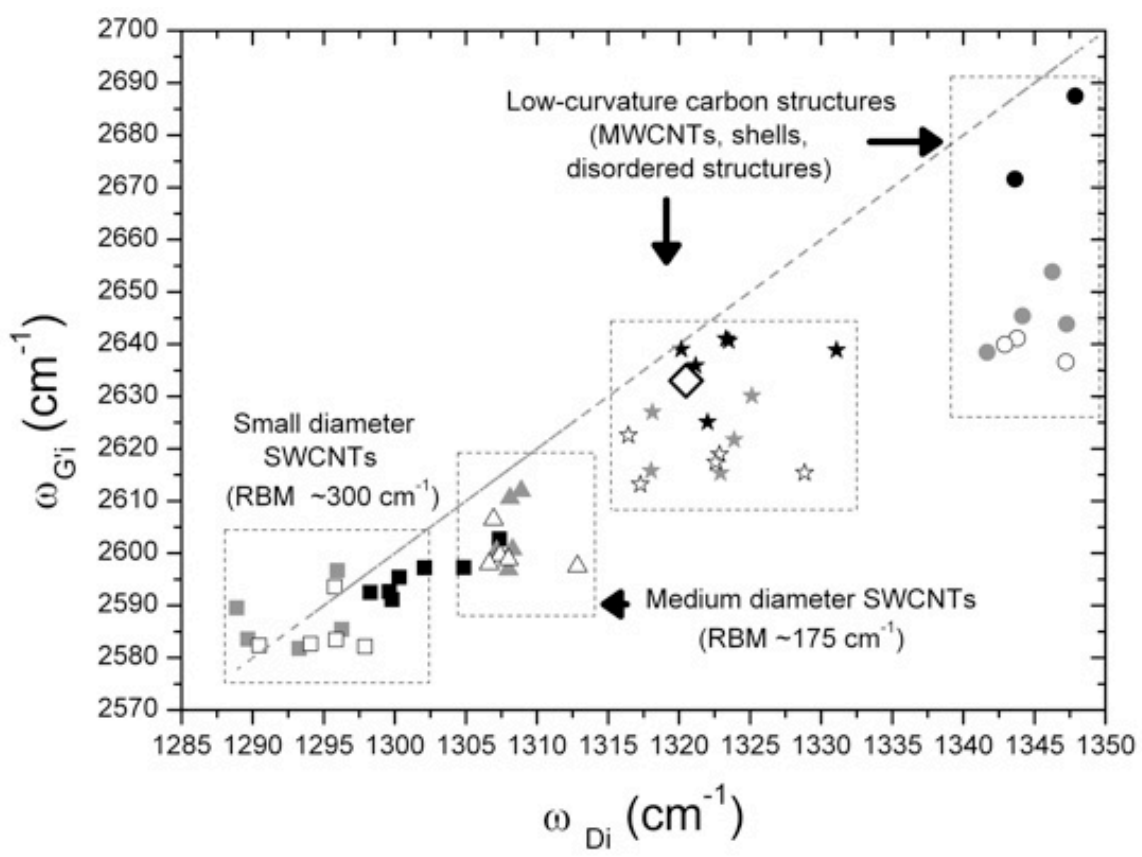

Figure 2. Position frequency of $\mathrm{G}^{\prime}{ }_{i}$ components as a function of the associated $\mathrm{D}_{\mathrm{i}}$ component $(\mathrm{i}=$ $1,2,3,4$ ) for samples grown with $\mathrm{C}_{2} \mathrm{H}_{2}$ (black symbols) or $\mathrm{EtOH}$ (grey and open symbols) with $\mathrm{Co} / \mathrm{SiO}_{2}$. The dash line illustrates the relation expected if $\omega_{\mathrm{G}}=2 \omega_{\mathrm{D}}$. The laser energy is $1.92 \mathrm{eV}$. The diamond symbol indicates the reference frequencies of graphene.

\section{DISCUSSION}

Different hypotheses can be considered for the attribution of the components of the $\mathrm{D}$ and G' bands observed in these CCVD-grown CNT samples. For instance, the D-band of CNT samples is sensitive to chemical grafting. Romanos et al. [15] showed that typical chemical addends desorb from SWCNT between 100 and $900^{\circ} \mathrm{C}$. To test this hypothesis, we submitted CNT samples to a thermal annealing under argon up to $950^{\circ} \mathrm{C}$. However, we did not observe a significant modification of the D and G' bands as observed by Romanos et al. in the case of highly functionalized SWCNTs.

Charged defects caused by substitutional dopants were reported by Maciel et al. [16] to induce an additional $G^{\prime}{ }_{D}$ component in the G' band beside the main $G_{P}$ peak of pristine SWCNTs. To test this hypothesis, we calculated the positions of the G' ${ }_{P}$ and $G^{\prime}{ }_{D}$ peaks from the empirical relationships determined by Maciel et al. Following this line of reasoning, the low frequency component of G' could be attributed to the G' ${ }_{\mathrm{P}}$ peak of pristine SWCNTs of small diameters while the higher-frequency $\mathrm{G}^{\prime}{ }_{\mathrm{i}}$ components could be attributed to two $\mathrm{G}_{\mathrm{D}}$ bands associated with p-type dopants. However, since there is no source of p-doping in our growth conditions contrary to the syntheses of Maciel et al., we also rejected this hypothesis.

The frequencies of the D and G' of SWCNTs are known to depend on the tube diameter [8]. Compared to graphene, one can expect a downshift of $0-30 \mathrm{~cm}^{-1}$ for a SWCNT sample (depending on the diameter distribution). Considering our samples, only the $\mathrm{D}_{\mathrm{i}}$ and $\mathrm{G}^{\prime}{ }_{i}$ components with frequencies lower than those of graphene could be attributed to SWCNTs and to the diameter effect. For instance, the $\left(\mathrm{D}_{1}, \mathrm{G}^{\prime}{ }_{1}\right)$ components could be attributed to SWCNTs of very small diameter $(\mathrm{d} \sim 0.7-0.8 \mathrm{~nm})$ while the $\left(\mathrm{D}_{2}, \mathrm{G}_{2}{ }_{2}\right)$ components could be attributed to SWCNTs of intermediate diameters $(\mathrm{d} \sim 1.4-1.8 \mathrm{~nm})$ (Figure 2). This interpretation correlates 
remarkably well with the RBM profiles at the same laser energy: at $647 \mathrm{~nm}$, samples grown with ethanol display both small-diameter semiconducting tubes and large-diameter metallic tubes in their RBM profile and display both the $\left(D_{1}, G^{\prime}{ }_{1}\right)$ and $\left(D_{2}, G^{\prime}{ }_{2}\right)$ components. Due to the separation of the metallic and semiconducting branches in the Kataura plot, this interpretation would also account for the possibility to resolve the $\left(D_{1}, G^{\prime}{ }_{1}\right)$ and $\left(D_{2}, G^{\prime}{ }_{2}\right)$ components.

However, the $\left(D_{i}, G^{\prime}{ }_{i}\right)$ components with frequencies higher than graphene cannot be attributed to SWCNTs. If one looks to the D-band frequencies of different $\mathrm{sp}^{2}$ materials [9-13], only graphitic materials have $G$ ' bands higher in frequency than graphene. As demonstrated by studies of multi-layer graphene [17], stacking causes the $G^{\prime}$ band of graphitic materials to become a multi-peak structure whose average position is upshifted compared to the $G$ ' peak of graphene. For defective graphitic materials, these features are averaged and the G' band appears as a single broad band. To test this hypothesis, we transferred CNT samples to TEM grids for HRTEM analysis. As shown in Figure 3, these CNT samples grown with $\mathrm{Co} / \mathrm{SiO}_{2}$ not only SWCNT but also an abundant amount of large-diameter multi-wall carbon filaments, especially at low growth temperatures. This observation is well correlated with the decrease of the highfrequency components of D and G' with increasing growth temperature. Such a transition from MWCNT at low temperature to SWCNT at high temperature is often reported in the nanotube literature [18]. It is worth mentioning that such multi-walled structures are not always the dominant carbon impurities of SWCNT samples: our previous HRTEM investigations showed that defective single-walled carbon structures were the dominant by-products of SWCNT samples grown with $\mathrm{Ni} / \mathrm{SiO}_{2}$ as catalyst $[19,20]$. Our AFM characterization actually shows that large $(\sim 10 \mathrm{~nm})$ catalyst particles are formed during the calcination pre-treatment of $\mathrm{Co} / \mathrm{SiO}_{2}$, contrary to $\mathrm{Ni} / \mathrm{SiO}_{2}$ which displays little change of surface roughness.

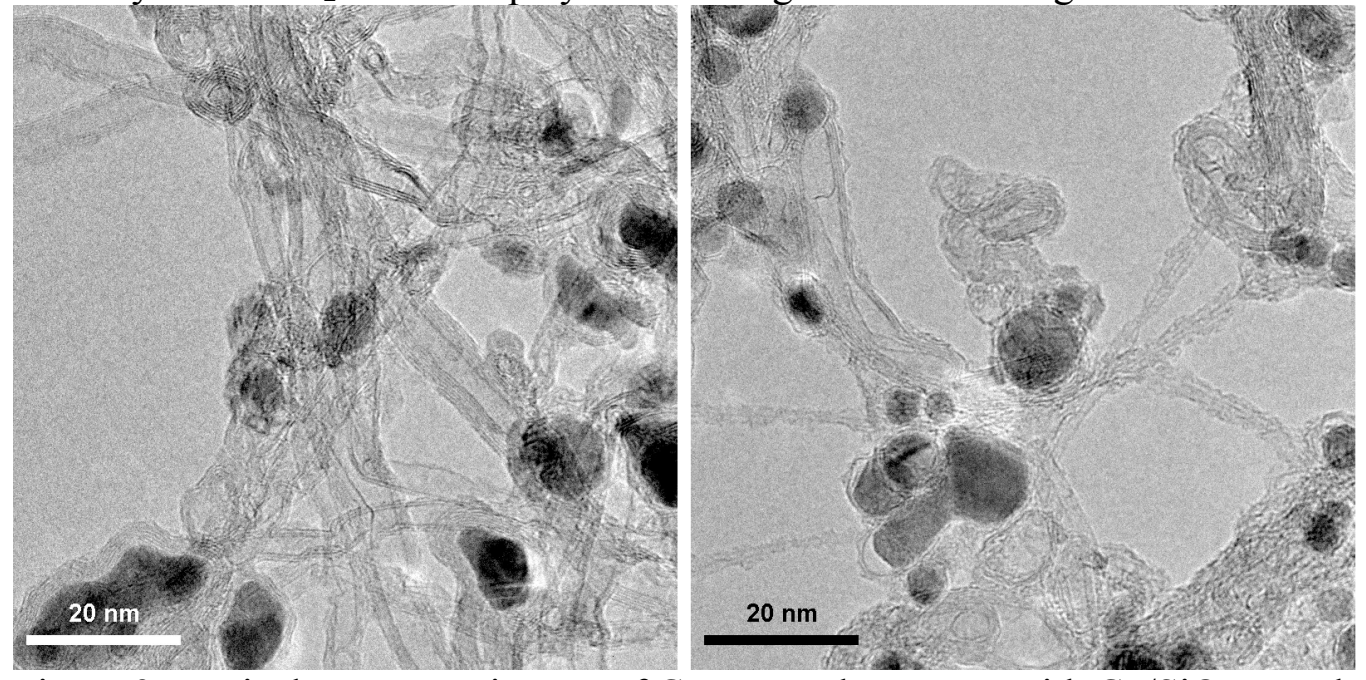

Figure 3. Typical HRTEM pictures of CNT samples grown with $\mathrm{Co} / \mathrm{SiO}_{2}$ sample and $\mathrm{EtOH}$ as carbon precursor at (a) low-temperature $\left(615^{\circ} \mathrm{C}\right)$ and $(\mathrm{b})$ high temperature $\left(800^{\circ} \mathrm{C}\right)$.

\section{CONCLUSIONS}

Contrary to SWCNTs, large MWCNTs and defective carbonaceous structures do not display a huge resonant Raman enhancement. This causes the Raman spectra of SWCNT samples to remain largely dominated by SWCNT features (i.e. intense RBMs, $\mathrm{G}^{+}$at $1590 \mathrm{~cm}^{-1}$, wellresolved and intense $\mathrm{G}^{-}$shoulders) even for high contents of other carbonaceous species. Indepth analysis of the $\mathrm{D}$ and $\mathrm{G}^{\prime}$ bands can allow one to identify the specific contributions of each carbon species. Experimentally, the D and G' bands display correlated spectral profiles as a 
function of the growth temperature: in both cases, the high-frequency components tend to disappear with increasing growth temperature. The $\mathrm{D}_{i}$ and $\mathrm{G}_{i}{ }_{i}$ components lying below the reference positions of graphene can be attributed to SWCNTs as expected from the diameter dependence of $\omega_{\mathrm{D}}$ and $\omega_{\mathrm{G}}$, for SWCNTs. HRTEM characterization support that the $\left(\mathrm{D}_{\mathrm{i}}, \mathrm{G}^{\prime}{ }_{\mathrm{i}}\right)$ components with frequencies higher than graphene correspond to disordered carbonaceous species present as impurities in SWCNT samples. In the case of samples grown with $\mathrm{Co} / \mathrm{SiO}_{2}$, the main by-products are large-diameter multi-walled carbon nanotubes.

\section{ACKNOWLEDGMENTS}

The authors acknowledge financial support from the Agence Nationale de la Recherche (P3N project "SOS Nanotubes" ANR-09-NANO-028).

\section{REFERENCES}

1. M. Dresselhaus, A. Jorio, A. Souza Filho and R. Saito, Philos T R Soc A 368 (1932), 53555377 (2010).

2. M. Pimenta, G. Dresselhaus, M. S. Dresselhaus, L. Cancado, A. Jorio and R. Saito, Phys. Chem. Chem. Phys. 9 (11), 1276-1290 (2007).

3. F. Tuinstra and J. Koenig, J. Chem. Phys. 53, 1126-1130 (1970).

4. F. Tuinstra and J. Koenig, Journal of Composite Materials 4 (4), 492-499 (1970).

5. M. S. Dresselhaus, G. Dresselhaus, R. Saito and A. Jorio, Phys. Rep. 409 (2), $47-99$ (2005).

6. S. Reich, C. Thomsen and J. Maultzsch, Carbon Nanotubes: Basic Concepts and Physical Properties, 1st Edition ed. (Wiley-VCH, Berlin, 2004).

7. M. Lucchese, F. Stavale, E. Ferreira, C. Vilani, M. Moutinho, R. B. Capaz, C. Achete and A. Jorio, Carbon 48 (5), 1592-1597 (2010).

8. A. Souza Filho, A. Jorio, G. G. Samsonidze, G. Dresselhaus, M. Pimenta, M. Dresselhaus, A. K. Swan, M. Ünlü, B. Goldberg and R. Saito, Phys. Rev. B 67 (3), 035427 (2003).

9. P. H. Tan, S. Dimovski and Y. Gogotsi, Philos T R Soc A 362 (1824), 2289 (2004).

10. Z. Xu, L. Chen, L. Liu, X. Wu and L. Chen, Carbon 49 (1), 350-351 (2011).

11. M. Matthews, M. Pimenta, G. Dresselhaus, M. Dresselhaus and M. Endo, Phys. Rev. B 59 (10), 6585-6588 (1999).

12. I. Pócsik, M. Hundhausen, M. Koós and L. Ley, J. Non-Cryst. Solids 227, 1083-1086 (1998).

13. A. C. Ferrari and J. Robertson, Philos T R Soc A 362 (1824), 2477-2512 (2004).

14. M. Picher, H. Navas, R. Arenal, E. Quesnel, E. Anglaret and V. Jourdain, Carbon 50 (7), 2407-2416 (2012).

15. G. E. Romanos, V. Likodimos, R. R. N. Marques, T. A. Steriotis, S. K. Papageorgiou, J. L. Faria, J. L. Figueiredo, A. n. M. T. Silva and P. Falaras, J. Phys. Chem. C 115 (17), 8534-8546 (2011).

16. I. O. Maciel, N. Anderson, M. A. Pimenta, A. Hartschuh, H. H. Qian, M. Terrones, H.

Terrones, J. Campos-Delgado, A. M. Rao, L. Novotny and A. Jorio, Nature Mat. 7 (11), 878-883 (2008).

17. A. C. Ferrari, J. C. Meyer, V. Scardaci, C. Casiraghi, M. Lazzeri, F. Mauri, S. Piscanec, D. Jiang, K. S. Novoselov, S. Roth and A. K. Geim, Phys. Rev. Lett. 97 (18), 187401 (2006).

18. D. B. Geohegan, A. A. Puretzky, I. N. Ivanov, S. Jesse, G. Eres and J. Y. Howe, Appl. Phys. Lett. 83, 1851 (2003).

19. M. Picher, E. Anglaret, R. Arenal and V. Jourdain, Nano Lett. 9 (2), 542-547 (2009).

20. M. Picher, E. Anglaret, R. Arenal and V. Jourdain, ACS Nano 5, 2118-2125 (2011). 